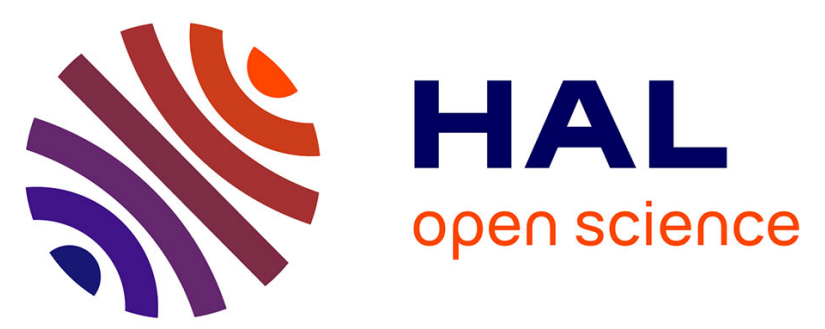

\title{
A Collaborative Architecture for Supply Chain Transparency Based on EPCIS Standard and MongoDB
}

\author{
Giulia Bruno, Vincenzo Viola
}

\section{To cite this version:}

Giulia Bruno, Vincenzo Viola. A Collaborative Architecture for Supply Chain Transparency Based on EPCIS Standard and MongoDB. 17th Working Conference on Virtual Enterprises (PRO-VE), Oct 2016, Porto, Portugal. pp.599-607, 10.1007/978-3-319-45390-3_51. hal-01614604

\author{
HAL Id: hal-01614604 \\ https://hal.inria.fr/hal-01614604
}

Submitted on 11 Oct 2017

HAL is a multi-disciplinary open access archive for the deposit and dissemination of scientific research documents, whether they are published or not. The documents may come from teaching and research institutions in France or abroad, or from public or private research centers.
L'archive ouverte pluridisciplinaire HAL, est destinée au dépôt et à la diffusion de documents scientifiques de niveau recherche, publiés ou non, émanant des établissements d'enseignement et de recherche français ou étrangers, des laboratoires publics ou privés. 


\title{
A Collaborative Architecture for Supply Chain Transparency based on EPCIS Standard and MongoDB
}

\author{
Giulia Bruno $^{1}$, Vincenzo Viola ${ }^{2}$ \\ ${ }^{1}$ Politecnico di Torino, Department of Management and Production Engineering, \\ Corso Duca degli Abruzzi 24, 10129 Torino, Italy \\ giulia.bruno@polito.it \\ 2 Antecs srl, Via Buzzi, 4, 20017 Rho, Milano, Italy \\ vviola@antecs.it
}

\begin{abstract}
Transparency is a fundamental requirement for granting the safety and quality of products along the whole supply chain. To reach such objective, a great collaboration along the actors of the supply chain is required. Radio Frequency Identification (RFID) and other pervasive computing technologies are able to generate event data to keep track of how physical entities pass through different parties of the supply chain processes. Recently, the Electronic Product Code Information Services (EPCIS) standard was introduced to enable the sharing of such events across supply chains. Works presented in literature are mainly focused on enabling technologies, with less emphasis on assessing how the available information can be used for a control at a higher level. In this paper, we present a collaborative architecture allowing the traceability of information about products throughout the entire supply chain by exploiting both the EPCIS standard and a NoSQL database. An application showing the potentiality of the proposed system in a case study is also reported.
\end{abstract}

Keywords: Collaborative supply chain, transparency, traceability, GS1, EPCIS, RFID, NoSQL, MongoDB.

\section{Introduction}

Today, consumers pay more and more attention to product quality, and especially in the food sector, they are interested in knowing the origin of the product and its pathway from the producer to the final seller. Consumers are oriented to chose products basing on the credence attributes rather than the price, and fraud and counterfeiting cause the lost of consumers' trust. For this reason, the problem of integrating data through the supply chains is becoming an important research topic. The safety and trust of consumers have to be guaranteed, and a strong collaboration along the supply chain is needed.

By recording product transitions, Barcodes and Radio Frequency Identification (RFID) have provided partial solutions to this issue [1,2]. Traceability of food product in supply chain has gained considerable importance, particularly following a number of food safety cases during delivery [3]. However, companies and organizations today 
are not able to manage an extended network of suppliers and distributors. Thus, fraud and counterfeiting are arising and are difficult to discover.

The Electronic Product Code Information Services (EPCIS) is a standard that provides specifications to assure product traceability [4]. The collection and analysis of product information allows supply chains to be virtualized and remotely monitored, optimized and controlled [5]. However, tracking a product is not enough to grant its quality. All the roles involved have to incrementally provide additional information regarding the product stages. EPCIS proposes a mechanism to exchange and share data but the semantics of data is informally defined and its interpretation is left up to the individual implementing engines [6].

Works presented in literature are mainly focused on enabling technologies, without addressing the usage of the generated information for control at a supply chain level. In this paper, a collaborative architecture is presented, which allows the traceability of information throughout the entire supply chain. Such architecture exploits the EPCIS standard to capture events related to products and a non-relational database to store them.

The paper is structured as follows. Section 2 revises the main literature available on this topic. Section 3 defines the food supply chain and presents the transparency problem. Section 4 describes the EPCIS standard by highlighting its capabilities and possible extensions. In Section 5, the collaborative architecture to grant transparency in supply chain is proposed, while Section 6 reports an application to a case study. Finally, Section 7 illustrates conclusions and states future works.

\section{Related Works}

Several researchers related to food traceability have already been done, especially related to the introduction of RFID technology in the agrifood industry [7]. Works on virtualized supply chains exploited to design traceability systems for foods provide systems to track the location of certain items and trace their history [5].

Examples of application of EPCIS for food product traceability are described in several works for different products. RFID technology was used together with wireless sensor networks in the wine production for monitoring the vineyards [8]. In the fish market, traceability systems based on EPCIS to store and manage fish information from farmer to retailer were studied $[9,10]$.

In the meat supply chain, due to recent meat crises and scandals, reference architectures based on EPCIS standard to grant transparency were presented $[11,12,13]$. Some works also investigate the best way of representing EPCIS events to enhance query efficiency, e.g., by means of a graph structure [14].

The EPCIS standard is also adopted for traceability of other kinds of products, e.g. in the pharmaceutical domain, to grant the security of the drug supply chain $[15,16]$. 


\section{Transparency Problem in Food Supply Chain}

Different kinds of companies are involved in a food supply chain, each of them operating in different markets and selling different products [17]. The food supply chain includes five main stages, as shown in Fig.1: production, processing, storage, distribution and retail. Physical items are exchanged among the stages (solid lines), while data collected in each stage are not exchanged neither follow a coherent standard.

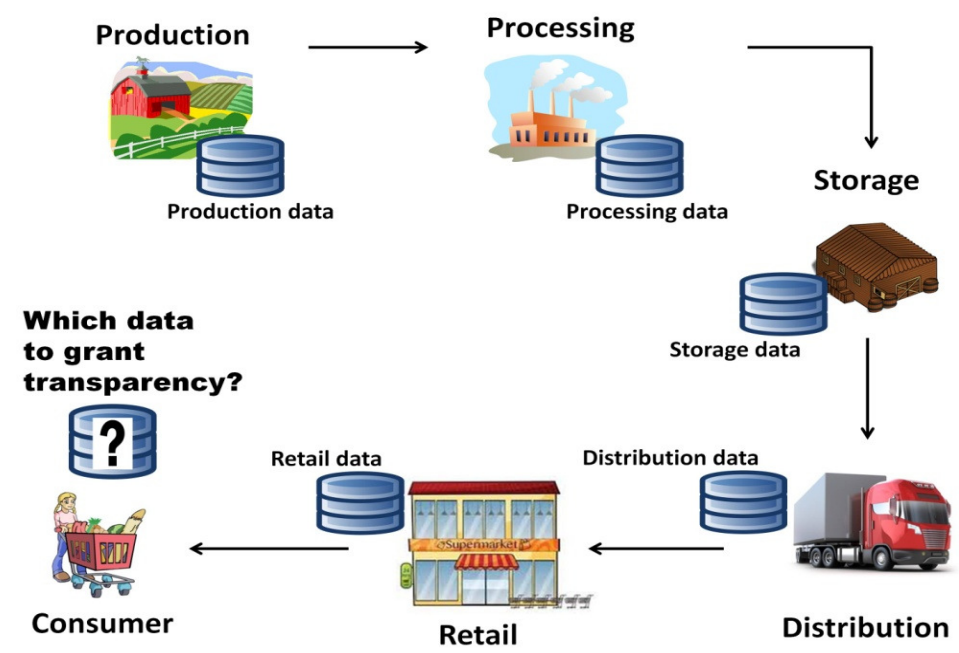

Fig. 1. Sectors included in the food supply chain.

As a result, the consumer is not aware of the process followed by the product during the previous stages, but also that production or processing companies do not have information regarding storage, distribution and retail.

The lack of communication across the stages clearly affect the trust of the chain, since each actor is not aware of the history of the product during the other stages. In fact, the managers of the companies in the production or processing stages are interested in knowing if the products are correctly stored and distributed along the supply chain. Thus, they need to know when their products arrive to the storages, how long remain there, how long is the journey to the retails, etc. Also the managers of retail companies are interested in information collected during other stages, such as the origin of the products they sell in order to trust their quality. Furthermore, all these information are of interest also for the final customer. 


\section{EPCIS Standard for Product Tracking}

The Electronic Product Code Information Services (EPCIS) is a standard defined by GS1, a not-for-profit international organization which provides specifications for the representation of product traceability information. It also develops several global standards to facilitate end-to-end traceability and information sharing [4].

EPCIS provides a data model serialized as an XML schema for capturing information artefacts that encapsulate the geographical progress and status of an item or set of items during the different phases of the supply chain. This is achieved by capturing data generated through the scanning of a barcode or RFID tag and encapsulating it as an event.

\subsection{EPCIS Events}

Accordingly to EPCIS 1.1 [18] four core event types are defined:

- ObjectEvent, used to register a general event occurring to a physical or digital object;

- AggregationEvent, used to indicate a physically aggregation objects (i.e., objects that are physically constrained to be in the same place at the same time, such as items in a pallet);

- TransformationEvent, used when a set of input objects are consumed and transformed in output objects;

- TransactionEvent, used when one or more objects are linked or delinked with business transactions.

The field of each event represent the four possible dimensions of an EPCIS event (i.e., what, when, where and why). Particularly they contain information regarding (1) the physical or digital objects participating in the event, (2) the period of time in which the event occurred, (3) the location in which the event was registered, and (4) the business context of the event. The meaning of the dimensions varies depending on the event type.

In addition to the basic EPCIS types, the standard can be extended by specific organizations to make it more suitable to their business. In fact, every event has an extension point, which can be used to attach additional data. Even if EPCIS specification proposes a mechanism to exchange and share data, the XML schema defines only the structure of the data to be recorded, while the semantics of data is informally defined and its interpretation is left up to the individual implementing engines [6]. Therefore, additional information regarding the four dimensions of the event (e.g., temperature, humidity, etc.) can be collected and stored. 


\subsection{Core Business Vocabulary}

Together with EPCIS, GS1 defined the Core Business Vocabulary (CBV), which defines specific data values to populate part of the EPCIS data model. CBV includes two different vocabularies, Standard Vocabulary and User Vocabulary.

The definition and meaning of the elements of the Standard Vocabulary are agreed in advance by the partners compliant with the standard. For example, the EPCIS standard defines the field "business step," whose possible values (e.g., shipping, receiving) are defined in the Standard Vocabulary. Standard Vocabularies are defined for the following fields of EPCIS: business steps, dispositions, business transaction types, and source and destination types.

On the contrary, the vocabularies of the User Vocabulary are controlled by a single organization, which has not constraints in deciding their meaning. While the CBV does not specify particular user vocabulary elements, it recommends syntax templates for the end users in defining their own elements. User Vocabularies can be defined for the following fields of the EPCIS standard: physical or digital objects, locations including both read points and business locations, business transaction identifiers, source/destination identifiers, and transformation identifiers.

\section{Collaborative Architecture to Grant Transparency}

The collaborative architecture proposed to grant transparency across the supply chain is shown in Fig.2. In addition to the solid lines showing the item flow, the information flows are shown as dotted lines. Red thin dotted lines represent exchange of EPCIS events, while green large dotted lines represent exchange of transparency information. Each actor involved in the supply chain uses the EPCIS standard to capture events related to products. The captured EPCIS events are sent to the Product tracking platform, where they are stored and analyzed.

The product tracking platform consists of three main elements: the event capturing interface, the EPCIS data repository and the query interface. The capture interface receives the EPCIS events captured by the companies in the supply chain. Procedures of event captures are custom logic specific for each company. An EPCIS event, while containing the information regarding the product identifier, also includes information regarding the business context in which data is obtained.

The captured EPCIS events are stored in a data repository. Due to the fact that EPCIS events can be easily translated into JSON format [14] and that the efficiency of non-relational versus relational databases in managing EPCIS data was recently proven [19], the data repository is implemented in a NoSQL database, particularly MongoDB [20].

Through the query interface, the applications interact with the data repository in which all the EPCIS events are stored and organized. Through a mobile App the consumer is able to read the EPC of the product of interest and consult the transparency information stored related to the product. Some information are valid for each product, such as the times and places the product crossed during its lifetime 
Other information vary from one product to another. For example, for a frozen food, the temperature range at which the product was kept can be retrieved.

Not only the customer can access to the stored information, but also all the other companies of the supply chain can control the events occurred to the products during the previous or following stages. In this way the transparency of the supply chain is granted not only for the consumer but also to all the companies involved.

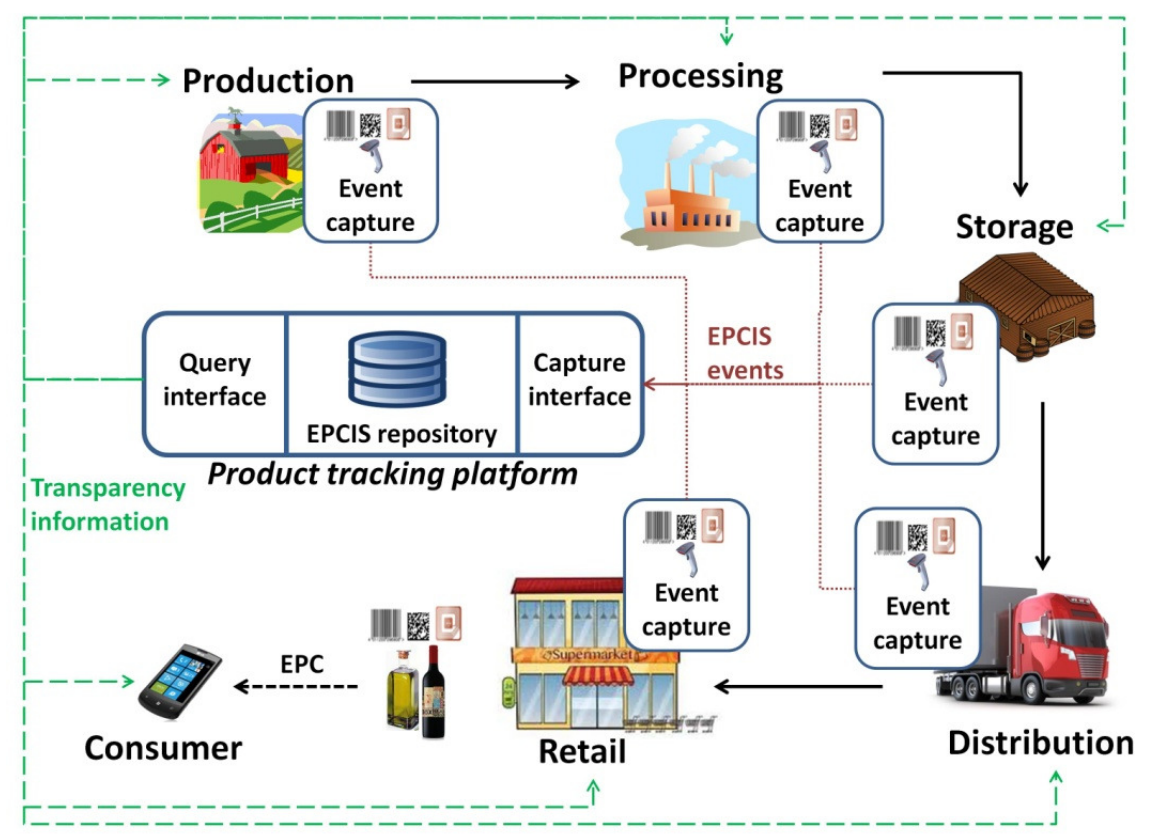

Fig. 2. Collaborative architecture based on a EPCIS product tracking platform.

\section{Application}

An example of the XML document used to capture an EPCIS event related to the creation of a wine bottle is shown in the following.

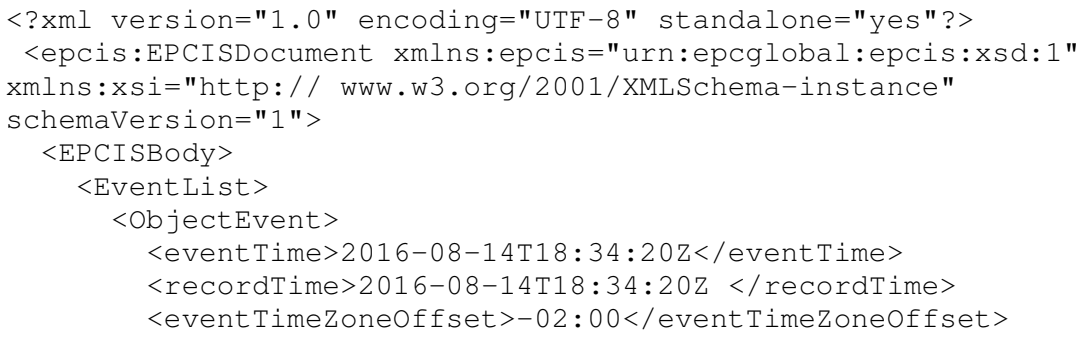




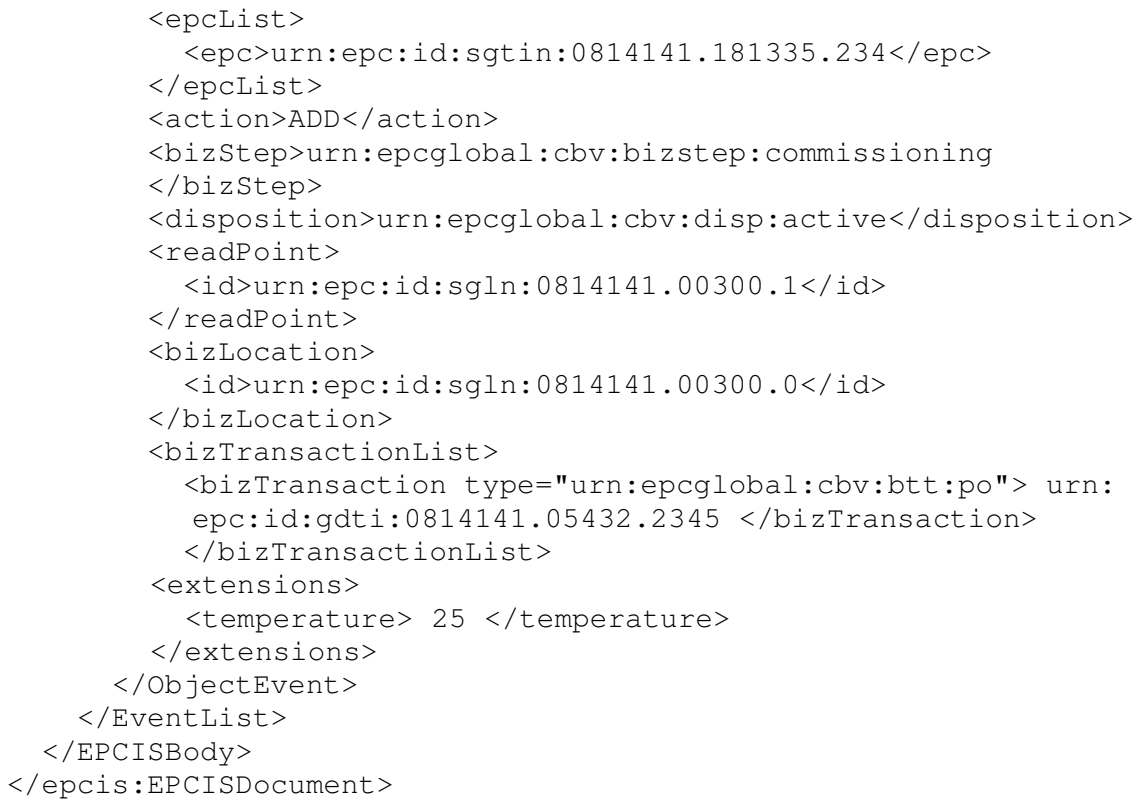

In the body of the document, a list of EPCIS event can be registered. In this case a single EPCIS event is represented. In an event, a list of product can be involved, but in this case a single product is considered. The product is identified by its EPC, which is codified through the Serialized Global Trade Item Number (SGTIN) standard. For each event the kind of action (add, delete or observe) is specified.

Then, information regarding the business stem (bizStep) and disposition are given, accordingly to the CBV definitions. The identification of the EPC reader (readPoint) and of the location at which the event is registered are also reported. To each event, a set of transaction can be associated, identified by their Global Document Type Identifier (GDTI). Finally, the user-defined extensions can be set. In this case, the additional information coming from a temperature sensor is included.

The EPCIS event is translated into a JSON document to be stored in MongoDB. The JSON document corresponding to the previous XML document is the following.

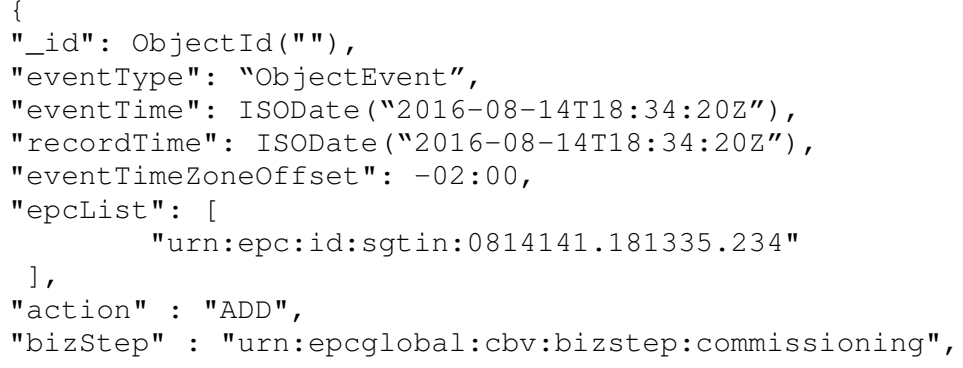




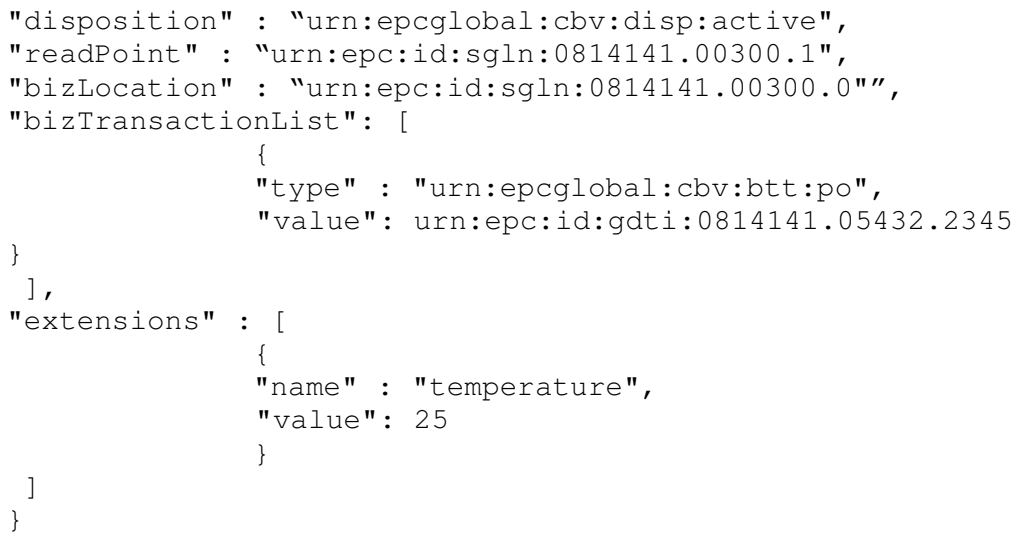

By having all the events stored in MongoDB in a collection named events, the query to retrieve all the events related to the product of interest of EPC code X in which the wine was observed at a temperature higher that 30 degrees is the following.

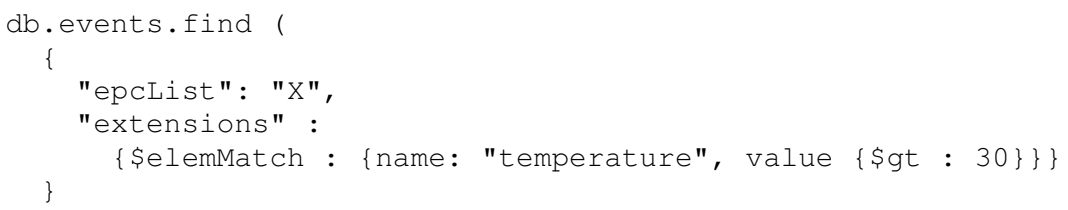

\section{Conclusion}

In this paper, a collaborative architecture allowing the traceability of products along a whole supply chain is presented. The trust of actors belonging to the supply chain is granted by the adoption of the EPCIS standard, maintained by the GS1 organization. All the captured EPCIS events are stored in a NoSQL data repository, particularly MongoDB. The storage of such data allow the execution of specific queries to retrieve tracking information regarding products.

Currently, only few extensions to the standard attributes were proposed, mainly connected to environmental variables such as temperature. Depending on the kind of products, more structured set of extensions can be designed, thus allowing a differentiation of information coming from different phases of the supply chain. For example, a set of organoleptic properties observed in the products can be stored in the production phase, while the set of machining parameters can be stored in the processing phase. Furthermore, new fields can be added to the events, such as an identification of the person that is responsible of an event, and also new kinds of events can be defined, in addition to the standard ones. 
Future works will address the investigation of useful extensions to enrich the EPCIS standard and the related queries to retrieve information of interest for different aspects of the product.

\section{References}

1. Kelepouris, T., Pramatari, K., \& Doukidis, G. (2007). RFID-enabled traceability in the food supply chain. Industrial Management \& Data Systems, 107(2), 183-200.

2. Solanki, M., Brewster, C. (2014) Modelling and Linking Transformations in EPCIS Governing Supply Chain Business Processes, E-Commerce and Web Technologies, Lecture Notes in Business Information Processing 188, 46-57.

3. Abdul Kadir, E., Shamsuddin, S.M., Supriyanto, E., Sutopo, W., Rosa, S.L. (2015) Food Traceability in Supply Chain Based on EPCIS Standard and RFID Technology, TELKOMNIKA Indonesian Journal of Electrical Engineering, 13(1), 187-194.

4. Främling, K., Parmar, S., Hinkka, V., Tätilä, J., Rodgers, D. (2013) Assessment of EPCIS Standard for Interoperable Tracking in the Supply Chain, Studies in Computational Intelligence 472, 119-134.

5. Verdouw, C.N., Wolfert, J., Beulens, A.J.M., Rialland, A. (2016) Virtualization of food supply chains with the internet of things, Journal of Food Engineering, 176, 128-136

6. Solanki, M., Brewster, C. (2015) OntoPedigree: Modelling pedigrees for traceability in supply chains, Semantic Web (published online).

7. Gandino, F., Rebaudengo, M., Sanchez, E.R. (2009) On Improving Automation by Integrating RFID in the Traceability Management of the Agri-Food Sector. IEEE Transactions On Industrial Electronics, 56(7), 2357-2365.

8. Exposito I, JA Gay-Fernandez, I Cuinas. A. (2013) Complete Traceability System for a Wine Supply Chain Using Radio-Frequency Identification and Wireless Sensor Network, IEEE Antennas and Propagation Magazine, 55(2), 255-267.

9. Hsu, Y.-C., Chen, A.P., Wang, C.-H. (2008) A RFID-Enabled Traceability System for the Supply Chain of Live Fish, IEEE International Conference on Automation and Logistics, 81-86.

10. Gunnlaugsson, V., Thakur, M., Forås, E., Ringsberg, H., Gran-Larsen, Ö., Margeirsson, S. (2011) EPCIS standard used for improved traceability in the redfish value chain, International Conference on Modern Information Technology in the Innovation Processes of the Industrial Enterprises, 182-192.

11. Kassahun, A., Hartog, R.J.M., Sadowski, T., Scholten, H., Bartram, T., Wolfert, S., Beulens, A.J.M. (2014) Enabling chain-wide transparency in meat supply chains based on the EPCIS global standard and cloud-based services, Computers and Electronics in Agriculture, 109, 179-190.

12. Thakur, M., Forås, E. (2015) EPCIS based online temperature monitoring and traceability in a cold meat chain, Computers and Electronics in Agriculture, 117, 22-30.

13. Kassahun, A., Hartog, R.J.M., Tekinerdogana, B. (2016) Realizing chain-wide transparency in meat supply chains based on global standards and a reference architecture, Computers and Electronics in Agriculture, 123, 275-291.

14. Byun, J., Kim, D. (2015) Enhanced Object Traceability on Unified and Linked EPCIS Events, Lecture Notes in Computer Science 9418, 232-246.

15. NamGung, K., Choi, Y., Park, S., Jun, C. (2012) The Development of e-Pedigree Model for Securing Transparent Pharmaceutical Distribution Channel in Korea, Convergence and Hybrid Information Technology, 226-234. 
16. Choi, J.B., Rogers, J., Jones, E. C. (2015) The impact of a shared pharmaceutical supply chain model on counterfeit drugs, diverted drugs, and drug shortages, Portland International Conference on Management of Engineering and Technology, 1879-1889.

17. Bukeviciute, L., Dierx, A. and Ilzkovitz, F. (2009) The functioning of the food supply chain and its effect on food prices in the European Union, European Economy, Occasional Papers, 47.

18. EPCIS 2014, EPC Information Services (EPCIS) Version 1.1 Specification, GS1 Standard Version 1.1, May 2014.

19. Kang, Y.-S., Park, I.-H., Rhee, J., Lee, Y.-H. (2016) MongoDB-Based Repository Design for IoT-Generated RFID/Sensor Big Data, IEEE Sensors Journal 16(2).

20. MongoDB, www.mongodb.com 